Article

\title{
Expectations of Bank Employees on the Influence of Key Performance Indicators and the Relationship with Job Satisfaction and Work Engagement
}

\author{
Angelika Lepold, Norbert Tanzer and Paulino Jiménez * (D) \\ Department of Psychology, University of Graz, 8010 Graz, Austria; angelika.lepold@edu.uni-graz.at (A.L.); \\ norbert.tanzer@uni-graz.at (N.T.) \\ * Correspondence: paul.jimenez@uni-graz.at; Tel.: +43-316-380-5128
}

Received: 25 May 2018; Accepted: 13 June 2018; Published: 19 June 2018

\begin{abstract}
Feedback systems of key performance indicators (KPIs) are crucial for companies to monitor their goals. To stay successful and to improve performance, the employees of a company are a potential resource as they build the link between resources and outcome. A hidden assumption in goal-setting is that the employees feel to have full influence on KPIs. Hence, employees' self-efficacy about believing in one's own capabilities and expectations about being able to influence KPIs are needed for organizational performance as well as high job satisfaction and work engagement. The present study examined whether influence expectations on KPIs can predict job satisfaction and work engagement above and beyond professional self-efficacy. Results from 136 bank employees in Austria showed that job satisfaction can be predicted by professional self-efficacy and influence expectations on bank-specific KPIs. Furthermore, professional self-efficacy, influence expectations on economic KPIs, and the influence expectations of the branch manager predicted work engagement. This study contributes to the importance of employees' belief in their own skills and in their influence on KPIs to be satisfied and engaged at work. Furthermore, it offers innovative and useful insights into the measurement of influence expectations.
\end{abstract}

Keywords: influence expectations; professional self-efficacy; job satisfaction; work engagement; bank employees

\section{Introduction}

Are you able to associate your work tasks with the goals of your company? Key performance indicators (KPIs) as one way to get insight into business operations are crucial for companies to monitor their progress toward self-defined goals (Hester et al. 2017), are relevant for management decisions (Collins et al. 2016), can be used to give positive or negative feedback to employees and to improve in different areas (Behn 2003), and provide an overview of the company's status (Maté et al. 2017). To stay successful and to improve performance, companies need to recognize humans as a potential important source as the output of employees affects the outcome of an organization (Behn 2003). One output of the work of employees can be customer satisfaction, which is also an important goal for organizations, especially in the banking sector (Ladeira et al. 2016). To give adequate feedback to the output of employees, many organizations have implemented feedback systems as monitoring systems that not only affect business units or branches but also single employees (Behn 2003). The rationale behind this is simple, as these business units and branches nearly get the same resources and so should produce the same outcomes (Gelade and Young 2005). These branches therefore can be compared to each other in reaching their goals. The link between the environmental resources and the outcome then is the human factor, mostly associated with the assumption that more engaged employees are more eager 
to reach the goals communicated through a feedback system of KPIs (Behn 2003). An assumption in goal-setting, which is often hidden, is that the employees feel that they have full influence on KPIs. Therefore, the expectations of having influence on KPIs may play a role. These influence expectations are in relation to professional self-efficacy as they can be defined as domain-related self-efficacy beliefs measuring a wide range of performances within work tasks (Bandura 2011). People having a high sense of self-efficacy and, working in a responsive environment that values their performance, show a high productive engagement and feel satisfied (Bandura 1997), likewise for employees in the banking sector (Sahibzada et al. 2016). Therefore, job satisfaction and work engagement play a fundamental role in organizational performance, as organizations wish thus to have engaged employees who devote their abilities and skills to their organization, since engaged employees are more productive (Bakker and Demerouti 2008).

This study investigates the relationship between professional self-efficacy and influence expectations on KPIs with job satisfaction and work engagement. We argue that influence expectations can predict job satisfaction and work engagement above and beyond professional self-efficacy. A higher belief in professional self-efficacy as well as into the ability to influence KPIs should lead to higher job satisfaction as well as to higher work engagement.

\subsection{Professional Self-Efficacy and Influence Expectations on Key Performance Indicators}

Self-efficacy is grounded in the social cognitive theory from Bandura and is defined as the individual's belief in his or her own capability for successful performance (Bandura 1997). General self-efficacy means a stable and broad sense of personal competence to deal with stressful situations (Luszczynska et al. 2005), whereas professional self-efficacy is specific to the work (Rigotti et al. 2008). As self-efficacy is not a global trait but rather a very differentiated construct about different belief systems, multidomain measures are indispensable (Bandura 2006). Therefore, people's belief in their skills is as different as their activity domains are, differing in forms and levels of self-efficacy. One can feel highly self-effective in leading a company, but has low self-efficacy in managing family life, so measuring self-efficacy multidimensional with different specific activity domains is more advantageous than using an overall-self-efficacy-measurement (Bandura 2011). Measuring self-efficacy in a domain-specific way is important to predict domain-specific future behavior, as measurements of self-efficacy are the best predictors for performance (Blomquist et al. 2016). Hence, task-specific self-efficacy is not a narrow construct for an isolated piece of work but concerns, for example, organizational productivity in a broad scope and therefore should be measured within an activity domain (Bandura 2011).

As organizational productivity often is measured with performance indicators in companies (Paul 1999), and self-efficacy is a predictor for performance (Blomquist et al. 2016), the question arises if people think that they can influence by themselves performance indicators of their company. We define the expectations of people to influence KPIs as "influence expectations" on KPIs. Influence expectations are in the Differentiated Expectancy-Value Model by Krampen classified into competence and control expectancies (Krampen 2000). The model assumes that specific situations lead to specific actions. These actions cause specific outcomes and thus lead to consequences. Every situation- and action-specific cognition is potentially generalized over time and across situations (Greve et al. 2001), where the situation-action-expectations and the action-outcome-expectations are subjective expectations of competence (an action is available in a specific situation) and control (an action leads to specific outcomes; Krampen 2000). Competence expectations are defined as the belief to behave competent in various situations and are in agreement with self-efficacy, and control expectancies refer to contingency expectancies of self-efficacy (Greve et al. 2001). Therefore, influence expectations consist of the expectations of an individual's own competence and the expectations of being able to control the situation (Krampen 2000). Influence expectations on KPIs thus include competence and control expectancies. Higher influence expectations on KPIs as a task specific instrument at work should like professional self-efficacy lead to behavior for getting desired outcomes. The expectancy as a subjective 
probability of an effort leads to performance (Vroom 1964) and, in this study, influence expectations on KPIs.

\subsection{Professional Self-Efficacy and Influence Expectations of Key Performance Indicators as Predictors of Job Satisfaction}

Job satisfaction can be seen as an outcome variable like in the measurement for well-being of employees (O'Driscoll and Brough 2010) representing their emotional state (Leka and Cox 2010). Job satisfaction can also be seen as a predictor for other job-related factors (e.g., absenteeism, performance, productivity, work engagement, organizational inefficiency (like counterproductive behavior), intention to quit, or commitment (Judge et al. 2017; Dormann and Zapf 2001; Jiménez et al. 2017)) in a dynamic process (Büssing and Bissels 1998; Jiménez 2006). Therefore, organizations want to explore the level of job satisfaction of their employees. Judge and Bono (2001) showed that generalized self-efficacy is a significant predictor for job satisfaction and performance in the work domain. Furthermore, positive correlations were found between professional self-efficacy and job satisfaction (Duffy and Lent 2009), concluding that individuals who are more confident in their own skills to perform show more job satisfaction (Rigotti et al. 2008; Federici 2013). A recent study also showed that professional self-efficacy leads to more satisfaction in the job (Maggiori et al. 2015). Influence expectations as a product of competence and control expectancies should also be related to job satisfaction. A person with lower competence expectations does not expect to be able to have solutions for certain problems at work (Heinrich 2004), which can lead to dissatisfaction (Kocak and Eves 2010). Therefore, lower influence expectations should lead to lower job satisfaction as an outcome: Influence expectations on KPIs should be positively predictive of job satisfaction above and beyond professional self-efficacy.

\subsection{Professional Self-Efficacy and Influence Expectations of Key Performance Indicators as Predictors of Work Engagement}

Work engagement is defined as an independent, persistent and pervasive motivationalpsychological state with a three-factor structure (Schaufeli 2018). Vigor refers to high levels of energy and mental resilience while working, a willingness to put effort into one's works, and persistence even when facing difficulties. Dedication reflects the involvement and psychological identification of an individual to his or her work, referring to a sense of significance, enthusiasm, inspiration, pride and challenge. Finally, absorption describes the extent of full concentration and engrossment in one's work when "time flies." Hence, work engagement is suggested to have advantages for the individual (e.g., enthusiasm and pride about work) and, as engaged employees are more productive, for organizations (Bakker and Demerouti 2008). Work engagement can lead to important competitive advantages by enhancing organizational performance (Chhetri 2017), and as self-efficacy is positively related to work engagement (Llorens et al. 2007), the appropriate measurement of self-efficacy is advantageous. Employees with higher self-efficacy are more ambitious, persist stronger even when facing difficulties, and show more motivation and energy (Wüpper and Lybbert 2017). We see influence expectations as a specific form of self-efficacy and as a product of competence and control expectancies, which should be linked to work engagement. As the belief in having control of our own behavior is linked to behavioral outcomes, self-efficacy should produce further valuable outcomes (Akinbobola and Adeleke 2013). Therefore, a specific measurement of self-efficacy is needed to predict specific future behavior. If people believe that they can influence KPIs, they will invest more effort and persist longer on a task. This increases the chance of a successful outcome (Tims et al. 2014). Hence, we hypothesize that influence expectations on KPIs will be positively predictive of work engagement above and beyond professional self-efficacy. 


\section{Method}

\subsection{Participants and Procedure}

The participants in this online survey were 136 employees of a bank. Participants having no contact to clients and working in the back office were excluded from the analysis. Among the employees were 62 women $(45.6 \%)$ and 74 men $(54.4 \%)$. The average age of participants was 42.3 years $(S D=11.1)$ and ranged from 21 to 61 years. The sample consisted of 31 employees in a leading position (22.8\%). The other 104 employees specified that they had no executive function $(76.5 \%)$, and one person did not specify their position in the bank $(0.7 \%)$.

The online-survey was advertised on the intranet of a bank in Austria. Bank employees were asked to participate in an online study about the influence on performance indicators and were promised total data protection. They were informed that the participation was completely voluntary, anonymous, and confidential. First, participants were asked to rate their influence expectations on three KPIs (randomized) via a percentage indication (influence expectations on economic KPIs). Second, they were asked to rate their personal influence expectations on further KPIs (influence expectations on bank-specific KPIs) via a rating-scale. In the next part, the participants rated their job satisfaction, their work engagement, and their professional self-efficacy. The last part asked for sociodemographic indicators, like sex, age, position, unit of organization, and contact to customers.

\subsection{Measures}

\subsubsection{Professional Self-Efficacy}

Professional self-efficacy was assessed with the six items of the Short Version of the Occupational Self-Efficacy Scale (Rigotti et al. 2008). Answers were obtained on a 6-point scale from 1 (completely true) to 6 (not at all true). The ratings were inverted for the further calculations, so that high ratings refer to high professional self-efficacy. A sample item is "I meet the goals that I set for myself in my job." Professional self-efficacy was generated as one general factor from all six single-items. Cronbach's alpha for professional self-efficacy was $\alpha=0.83$.

\subsubsection{Influence Expectations on Economic Key Performance Indicators}

To measure influence expectations on economic KPIs, two new measurements were developed. Therefore, the guideline to create self-efficacy scales by Bandura (2006) was considered. Self-efficacy scales are unipolar and should range from zero to a maximum. To get sensitive and reliable measures, items to measure self-efficacy should use a scale from 0 to 100 and should be formulated with "can do" as a judgment of capability and be tailored to activity domains.

Influence expectations on economic KPIs were measured for three indicators. The indicator Cost-Income-Ratio (CIR) describes the relation between expenses and income and explains how efficient a company is. The economic indicator Success-Oriented Relevance System (SOR) consists of all goals that are rated at the beginning of a year and should be reached at the end. The Gaining of New Customers (GNC) is also relevant for companies and the indicator consists of the number of new customers an employee has gained in one year. The influence expectations on the three indicators CIR, SOR and GNC were rated with the question "To what extent can the indicator be influenced by (a) myself as an employee, (b) the branch manager, (c) the regional manager, (d) the executive management, or (e) external factors (like economic situation, location)?" Employees were asked to give their answers for each of the indicators by dividing $100 \%$ to these five influence factors. Influence expectations on economic KPIs were calculated as mean for the three KPIs and for all five influence factors each. They are called (a) personal influence expectations $(\alpha=0.79),(b)$ influence expectations of the branch manager $(\alpha=0.69)$, (c) influence expectations of the regional manager $(\alpha=0.52)$, (d) influence expectations of the executive management $(\alpha=0.55)$, and $(\mathrm{e})$ influence expectations of external factors 
$(\alpha=0.53)$. As the sum is fixed and there are only four degrees of freedom, just the first four influence factors were used for regression analyses.

\subsubsection{Influence Expectations on Bank-Specific Key Performance Indicators}

To develop the items for influence expectations on bank-specific KPIs, also the guideline to create self-efficacy scales was used. In this guideline, another approach for scales to measure self-efficacy is a scale ranging from 0 to 10 (Bandura 2006). In a bank, bank-specific KPIs are of further interest. Therefore, 10 more indicators, only relevant in the banking sector, were rated for influence expectations of employees by themselves on a 10-point scale from $0 \%$ (no influence) to $100 \%$ (complete influence). The indicators were the sale of own emissions, the sale of savings, the sale of insurances, the sale of credit cards, the new volume funding, the customers demand saturation, the number of fund sales, the number of financial checks, the period of support, and the earnings of security papers. The employees were asked to rate their personal influence expectations on these ten indicators. Influence expectations on bank-specific KPIs were generated as one general factor from all ten single-items. The item period of support was excluded from further calculations because of a small item-total correlation (0.24). Cronbach's alpha for the nine remaining influence expectations on bank-specific KPIs was $\alpha=0.92$.

\subsubsection{Job Satisfaction}

The facets of job satisfaction were measured with the screening version of the Profile Analysis of Job Satisfaction (PAJS-Facet-Items; Lepold et al. forthcoming). Employees were asked to indicate their agreement for 15 items on a five-point scale $(1=$ very satisfied, $5=$ unsatisfied $)$. The ratings were inverted for further calculations, so that high ratings refer to high job satisfaction. The PAJS-Facet-Items (PAJS-FI) consists of 14 facets. A sample item is "I am ... [satisfied, rated from 1, very satisfied to 5, unsatisfied] with information and communication (activities in company, treatment of my suggestions, information from the management, information about innovations)." Job satisfaction was generated from all 14 facet-items, excluding the item "overall job satisfaction." In the present study, Cronbach's alpha for job satisfaction was $\alpha=0.86$.

\subsubsection{Work Engagement}

The short version of the Utrecht Work Engagement Scale (UWES) from (Schaufeli and Bakker 2003) was used to measure work engagement. The UWES-9 includes nine items pertaining to the three dimensions vigor, dedication, and absorption (three items for each dimension). Employees were asked to indicate their agreement on a seven-point scale from 0 (never) to 6 (always/every day). Sample items are "At my work, I feel bursting with energy" (dimension vigor), "I am proud on the work that I do" (dimension dedication), and "I feel happy when I am working intensely" (dimension absorption). In the present study, Cronbach's alpha for work engagement was $\alpha=0.95$.

\section{Results}

Data were analyzed using Version 24 of Statistical Package for Social Sciences (SPSS). All variables were transformed into z-values to get standardized variables.

In Table 1 the average percentage values for influence expectations on economic KPIs of all influence factors are shown. For the economic KPI CIR, influence expectations of the executive management showed on average the highest ratings, followed by personal influence expectations. By far the largest rating for the economic KPIs SOR and GNC was shown for personal influence on average. The smallest rating for all economic KPIs was found for influence expectations of the regional manager.

For influence expectations on bank-specific KPIs, employees rated on average their highest influence for financial checks $(M=77.3 \%, S D=30.2)$, saying that employees believe that they can with $77.3 \%$ on average personally influence the number of financial checks. Further means for influence expectations on bank-specific KPIs in descending order are number of sale of credit cards $(M=62.6 \%$, 
$S D=26.5)$, sale of insurances $(M=62.2 \%, S D=24.5)$, customers demand saturation $(M=57.7 \%$, $S D=28.2)$, sale of own emissions $(M=52.3 \%, S D=27.5)$, number of fund sales $(M=41.4 \%, S D=27.8)$, sale of savings $(M=46.6 \%, S D=28.1)$, earnings of security papers $(M=45.1 \%, S D=27.4)$, and new volume funding $(M=41.8 \%, S D=25.4)$.

Table 1. Means $(M)$ and standard deviations $(S D)$ for $\operatorname{IE}^{1}(\mathrm{~N}=136)$.

\begin{tabular}{|c|c|c|c|c|c|c|}
\hline \multirow[b]{2}{*}{ Influence Factors on Economic KPIs } & \multicolumn{2}{|c|}{$\mathrm{CIR}^{2}$} & \multicolumn{2}{|c|}{$\mathrm{SOR}^{2}$} & \multicolumn{2}{|c|}{$\mathrm{GNC}^{2}$} \\
\hline & $M$ & $S D$ & $M$ & $S D$ & $M$ & $S D$ \\
\hline $\mathrm{IE}^{1}:$ Personal influence & 20.7 & 16.0 & 39.9 & 19.3 & 34.1 & 18.3 \\
\hline $\mathrm{IE}^{1}$ : Branch manager & 17.6 & 10.0 & 18.6 & 11.7 & 18.6 & 10.9 \\
\hline $\mathrm{IE}^{1}$ : Regional manager & 16.9 & 9.6 & 12.2 & 8.5 & 9.9 & 8.0 \\
\hline $\mathrm{IE}^{1}$ : Executive management & 25.0 & 15.9 & 13.4 & 11.5 & 16.3 & 11.6 \\
\hline $\mathrm{IE}^{1}$ : External factors & 19.8 & 14.7 & 15.9 & 12.2 & 21.1 & 16.9 \\
\hline
\end{tabular}

${ }^{1} \mathrm{IE}=$ influence expectations on economic key performance indicators. ${ }^{2} \mathrm{CIR}=$ Cost-Income-Ratio; SOR $=$ SuccessOriented Relevance System, GNC = Gaining of New Customers. The sum of the means for CIR/SOR/GNC is $100 \%$.

Correlations and reliabilities for professional self-efficacy, influence expectations on economic KPIs and on bank-specific KPIs in a bank, job satisfaction, and work engagement are shown in Table 2. To interpret the correlation coefficients, the classification from (Cohen 1977) was used. Moderate correlations were found between professional self-efficacy and job satisfaction as well as work engagement. Small to moderate correlations were found between professional self-efficacy and personal influence expectations on economic KPIs and on bank-specific KPIs (positive) as well as influence expectations of the branch manager (negative). Furthermore, job satisfaction and personal influence expectations on economic KPIs as well as on bank-specific KPIs showed significant positive small to moderate correlations. Work engagement correlated negatively with influence expectations of external factors and positively with influence expectations on bank-specific KPIs (moderate). Influence expectations on bank-specific KPIs showed a moderate to strong positive correlation with personal influence expectations on economic KPIs and a negative correlation with influence expectations of the executive management (moderate to strong) and external factors on economic KPIs (small to moderate).

Furthermore, Table 2 shows Cronbach's alpha for the two measurements of influence expectations on KPIs. Cronbach's alpha for influence expectations on bank-specific KPIs is higher than for all influence expectations on economic KPIs.

\subsection{Professional Self-Efficacy and Influence Expectations of Key Performance Indicators as Predictors of Job Satisfaction}

To test if job satisfaction can be predicted by influence expectations above and beyond professional self-efficacy, a hierarchical regression analysis was conducted. The assumptions to calculate a hierarchical regression were all fulfilled. As it is known that professional self-efficacy is a predictor for job satisfaction, it was entered first in the model. The predictors personal influence expectations on economic KPIs and on bank-specific KPIs were entered in the second step. In a third step, influence expectations of the branch manager, the regional manager and of the executive management on economic KPIs were entered. As shown in Table 3, professional self-efficacy explains $10 \%$ of the variance in job satisfaction (Step 1). Additionally, $6 \%$ can be explained by personal influence expectations on economic and bank-specific KPIs (Step 2), although only personal influence expectations on bank-specific KPIs show a significant result. The three predictors branch manager, regional manager and executive management (Step 3) do not explain variance in job satisfaction. As such $16 \%$ of job satisfaction can be explained by professional self-efficacy and influence expectations on bank-specific KPIs. Standardized $\beta$-values show that professional self-efficacy $(\beta=0.25)$ is a more important predictor for job satisfaction than personal influence expectations on bank-specific KPIs $(\beta=0.18)$. 
Table 2. Correlations and reliability coefficients for professional self-efficacy, $\mathrm{IE}^{1}$ (economic and bank-specific), job satisfaction, and work engagement $(\mathrm{N}=136)$.

\begin{tabular}{|c|c|c|c|c|c|c|c|c|c|}
\hline & 1 & 2 & 3 & 4 & 5 & 6 & 7 & 8 & 9 \\
\hline 1. Professional self-efficacy & $(0.83)^{2}$ & & & & & & & & \\
\hline 2. IE ${ }^{1}$ : Personal Influence (economic) & 0.18 * & $(0.79)^{2}$ & & & & & & & \\
\hline 3. $\mathrm{IE}^{1}$ : Branch manager (economic) & $-0.18 *$ & $-0.25 * *$ & $(0.69)^{2}$ & & & & & & \\
\hline 4. $\mathrm{IE}^{1}$ : Regional manager (economic) & -0.06 & $-0.46^{* *}$ & $0.30 * *$ & $(0.52)^{2}$ & & & & & \\
\hline 5. IE ${ }^{1}$ : Executive management (economic) & 0.00 & $-0.60 * *$ & $-0.27 * *$ & 0.14 & $(0.55)^{2}$ & & & & \\
\hline 6. IE ${ }^{1}$ : External factors (economic) & -0.08 & $-0.41^{* *}$ & $-0.39 * *$ & $-0.30^{* *}$ & 0.08 & $(0.53)^{2}$ & & & \\
\hline 7. IE ${ }^{1}$ :Personal Influence (bank-specific) & 0.18 * & $0.40^{* *}$ & 0.13 & -0.14 & $-0.39 * *$ & $-0.24^{* *}$ & $(0.92)^{2}$ & & \\
\hline 8. Job satisfaction & $0.31^{* *}$ & $0.23^{* *}$ & -0.06 & -0.01 & -0.13 & -0.15 & $0.27 * *$ & $(0.86)^{2}$ & \\
\hline 9. Work engagement & $0.28 * *$ & 0.17 & 0.15 & 0.04 & -0.11 & $-0.28^{* *}$ & $0.26^{* *}$ & $0.57^{* *}$ & $(0.95)^{2}$ \\
\hline
\end{tabular}

${ }^{1} \mathrm{IE}=$ influence expectations on key performance indicators. ${ }^{2}$ Cronbach's $\alpha$ reliability coefficients are presented in the main diagonal in parentheses ${ }^{*} p<0.05$; ${ }^{* *} p<0.01$.

Table 3. Hierarchical regression analysis for job satisfaction and work engagement as outcome variables $(\mathrm{N}=136)$

\begin{tabular}{|c|c|c|c|c|c|c|c|c|}
\hline \multirow[b]{2}{*}{ Step and Predictor Variable } & \multicolumn{4}{|c|}{ Job Satisfaction $^{2}$} & \multicolumn{4}{|c|}{ Work Engagement $^{2}$} \\
\hline & $R^{2}$ & $\Delta R^{2}$ & $\beta$ & $s r$ & $R^{2}$ & $\Delta R^{2}$ & $\beta$ & $s r$ \\
\hline Step 1 & $0.10 * *$ & $0.10 * *$ & & & $0.08 * *$ & $0.08 * *$ & & \\
\hline Professional self-efficacy & & & $0.25^{* *}$ & $0.24 * *$ & & & $0.25 * *$ & $0.24^{* *}$ \\
\hline Step 2 & $0.15^{*}$ & $0.06^{*}$ & & & $0.12 *$ & $0.05 *$ & & \\
\hline IE ${ }^{1}$ : Personal Influence (economic) & & & 0.16 & 0.1 & & & $0.27 *$ & $0.16^{*}$ \\
\hline $\mathrm{IE}^{1}$ : Personal influence (bank-specific) & & & $0.18 *$ & $0.16^{*}$ & & & 0.16 & 0.14 \\
\hline Step 3 & 0.16 & 0.01 & & & $0.18 *$ & $0.05 *$ & & \\
\hline IE ${ }^{1}$ : Branch manager (economic) & & & -0.03 & -0.02 & & & $0.25 *$ & 0.20 * \\
\hline $\mathrm{IE}^{1}:$ Regional manager (economic) & & & 0.11 & 0.1 & & & 0.11 & 0.09 \\
\hline IE $^{1}$ : Executive management (economic) & & & 0.01 & 0.01 & & & 0.16 & 0.11 \\
\hline
\end{tabular}

${ }^{1} \mathrm{IE}=$ influence expectations on key performance indicators. ${ }^{2} \mathrm{sr}=$ semipartial correlation coefficient. ${ }^{*} p<0.05 ;{ }^{* *} p<0.01$. 


\subsection{Professional Self-Efficacy and Influence Expectations of Key Performance Indicators as Predictors of Work Engagement}

To test if influence expectations can explain work engagement above and beyond professional self-efficacy, a further hierarchical linear regression was conducted. The assumptions to calculate a hierarchical regression were as well all fulfilled. As it is known that professional self-efficacy is a predictor for work engagement, it was entered first in the model. The predictors personal influence expectations on economic KPIs and on bank-specific KPIs were entered in the second step. In a third step, influence expectations of the branch manager, the regional manager and of the executive management were entered. Table 3 shows that $8 \%$ of the variance for work engagement is explained by professional self-efficacy (Step 1). Additionally, 5\% (Step 2) can be explained by personal influence expectations, whereas only influence expectations on economic KPIs show a significant result. The influence expectations of the branch manager, the regional manager and the executive management (Step 3) explain further 5\%. However, only the branch manager shows significant results. A total $18 \%$ of work engagement can be explained by professional self-efficacy, influence expectations on economic KPIs, and influence expectations of the branch manager. Standardized $\beta$-values show that the three predictors of work engagement, namely personal influence expectations on economic KPIs $(\beta=0.27)$, professional self-efficacy $(\beta=0.25)$, and influence expectations of the branch manager $(\beta=0.25)$ have a comparable degree of importance in the model.

\section{Discussion}

This study examined if influence expectations on KPIs can explain job satisfaction and work engagement above and beyond professional self-efficacy. Hierarchical regression showed that for job satisfaction professional self-efficacy and influence expectations on bank-specific KPIs were the best predictors. For work engagement, professional self-efficacy, influence expectations on economic KPIs, and influence expectations of the branch manager were significant predictors.

\subsection{The Measurement of Influence Expectations on Key Performance Indicators}

Two measurements were designed to explore influence expectations on KPIs using the guideline to create self-efficacy scales (Bandura 2006). To measure influence expectations on economic KPIs, percentage values of different influence factors had to be rated by the employees. For the KPIs SOR and GNC the highest rating resulted for personal influence with $40 \%$ or $34 \%$, whereas for the KPI CIR personal influence was with $21 \%$ on the second place. For the KPI CIR, employees think that the executive management has the most influence above all other influence factors. The second way to measure influence expectations on bank-specific KPIs for personal influence was on a percentage scale from $0 \%$ to $100 \%$. There, the ratings ranged from $77 \%$ to $42 \%$ personal influence. It can be assumed that the more indicators are related to existing customers and contact to customers, the more the bank employees believe in personally being able to influence KPIs, whereby influence expectations on economic KPIs showed the lowest ratings of personal influence.

Comparing both measurements, the rating of influence expectations on KPIs with percentage values provides more differentiated results (economic KPIs), whereas the rating with a percentage scale is more efficient (bank-specific KPIs). By examining Cronbach's alpha, the coefficient for influence expectations on bank-specific KPIs is higher than for economic KPIs. Further research should examine if both measurements either for economics KPIs or for bank-specific KPIs lead to the same results of personal influence.

\subsection{Predicting Job Satisfaction with Professional Self-Efficacy and Influence Expectations on Key Performance Indicators}

Results showed that $16 \%$ of the variance in job satisfaction can be explained by professional self-efficacy and influence expectations on bank-specific KPIs. Professional self-efficacy being a predictor for job satisfaction is in line with previous research (e.g., Judge and Bono 2001; Federici 2013). 
Hence, being confident in one's own skills and abilities leads to higher job satisfaction (Duffy and Lent 2009). Influence expectations on bank-specific KPIs further showed to be a predictor for job satisfaction, whereas influence expectations on economic KPIs were not. Different reliabilities for the newly developed measurements must be taken in to account. As inefficient problem-solving capabilities at work are dissatisfying (Kocak and Eves) and are in the definition part of competence expectancies, the influence on economic KPIs might be lower (as the ratings for personal influence showed) and therefore are less related to job satisfaction. A further difference between these two expectations is the closeness to existing customers. The subjective economic KPIs compared to the bank-specific KPIs show less customer contact in existing relationships which might be an explanation for economic KPIs not being predictive for job satisfaction. Therefore we conclude that the influence expectations on bank-specific KPIs are an important predictor for job satisfaction.

\subsection{Predicting Work Engagement with Professional Self-Efficacy and Influence Expectations on Key Performance Indicators}

Results showed that $18 \%$ of the variance in work engagement can be explained by professional self-efficacy, influence expectations on economic KPIs, and influence expectations of the branch manager. In line with previous research, professional self-efficacy was a predictor for work engagement (Wüpper and Lybbert 2017). Self-efficacy may lead to a greater willingness to spend more energy on a task, to more task involvement and thus, to more engagement (Ouweneel et al. 2011). Indeed, self-efficacy is a self-motivating mechanism: When employees perceive their skills to be high, they set themselves goals and are motivated to spend effort and persistence even when facing difficulties to reach their goals (Guglielmi et al. 2012). Hence, the setting of meaningful goals can lead to more work engagement (Ouweneel et al. 2013). As KPIs are often installed to give adequate feedback to employees (Behn 2003), these can be seen as goals for employees. People who are not getting information and feedback about their performance, may not be fully motivated to change unsuccessful behavior or to show motivation concerning better performance (Bandura 2000). Furthermore, influence expectations on economic KPIs also were predictive of work engagement, whereas influence expectations on bank-specific KPIs were not. Influence expectations of economic KPIs did not predict job satisfaction, but work engagement, determining that the personal influence ratings for economic KPIs were much lower than for bank-specific KPIs. Different Cronbach's alpha must be further considered for this interpretation. Furthermore, influence expectations of the branch manager on economic KPIs were a significant predictor for work engagement. As the branch manager has the nearest contact to the employees and is present in every branch, it can be assumed that branch managers as direct supervisors have a strong influence on work engagement, but, as results reveal, has not on job satisfaction. As we know from different research, work engagement and job satisfaction are two different constructs (Warr and Inceoglu 2012) but are influenced by different factors. For work engagement, employees may assess their direct supervisors better than management (Kelloway and Barling 2010). Furthermore, it must be mentioned that people with a leading position were also included in the sample.

\subsection{Theoretical and Practical Implications}

Personal influence expectations on bank-specific KPIs can predict job satisfaction and personal influence expectations on economic KPIs can predict work engagement above and beyond professional self-efficacy. A feedback system with KPIs is an important tool to stay successful and to improve performance (Behn 2003), but the hidden assumption of employees to have influence on KPIs is not fully supported in this study. A first step for companies is to communicate KPIs, which are important to monitor their progress toward goals, to their employees and to teach them how KPIs matter in their daily work tasks. Employees with a higher sense of self-efficacy show a stronger relationship between work engagement and job performance than employees with low self-efficacy (Alessandri et al. 2015). Therefore, high self-efficacy is not only of interest for employees but also for companies. 
A further implication is the awareness of employees, that they can influence KPIs of their company. Therefore, practitioners in the human resources department should raise the awareness of influencing KPIs by considering a professional development to enforce the belief of people in one's own skills and in one's influence on KPIs. Interventions that may enhance people's professional self-efficacy and influence expectations on KPIs include e.g., mentoring or regular performance appraisal. Bandura (1997) names four sources of self-efficacy: Vicarious experience, verbal persuasion, physiological and affective states, and enactive mastery experience. As enactive mastery experiences are the most influential source of self-efficacy, it is crucial to let employees experience their success. Such an experience can be offered by supervisors giving positive feedback to their employees. Moreover, a specific feedback concerning KPIs may provoke an enhancement of influence expectations on KPIs. In this example, enactive mastery experience and verbal persuasion can be used to strengthen self-efficacy and influence expectations in one process.

Studies also revealed that the effect of self-efficacy on performance is positive when people get high rewards (Tzur et al. 2016). In conclusion, practitioners in the human resources department need to find a method to reward their employees in a reasonable way to enhance self-efficacy and influence expectations, and in a next step job satisfaction as well as work engagement which leads to higher performance.

\subsection{Limitations and Suggestions for Future Research}

The present study was conducted with employees in an Austrian bank. On one hand, the sample is a limitation because of the generalization of the results. To confirm the results, employees in other organizations and in different cultures as there are differences in collective-oriented and individual oriented cultures (Mau 2000) should be further explored. On the other hand, the used sample is a benefit as the bank employees were chosen because of their well-integrated KPIs in every bank branch. The employees already have a good knowledge about the goals presented with KPIs. Furthermore, every branch has the same KPIs and gets a feedback about their goal-reaching at the end of the year. So, the bank employees can be considered as experts for their KPIs.

Obviously, the banking industry was currently (at the time of the present study) in a crisis. There might be a negative influence, which reduced the rated level of self-efficacy of the employees working in banking industry. Furthermore, the employees in the bank showed very high ratings of job satisfaction, comparing to an Austrian comparative group (Jiménez et al. 2016), which could have affected the results. For measurements of self-efficacy, it is important that they are recorded privately without personal identification (Bandura 2006) which has been given in this study. But it might be interesting to see how financial and economic experts judge the influence expectations on KPIs for employees and if these ratings between experts and employees differ.

Furthermore, the topic about influence expectations on KPIs is a new one and there could be other methods to measure them, e.g., people could rate their influence expectations with a rating scale without percentages. Besides, influence expectations on KPIs were measured in two different ways. The percentage rating of influence expectations on economic KPIs was divided into five subgroups whereas influence expectations on bank-specific KPIs were only measured for personal influence with a percentage rating-scale. Further research should investigate if both measurements show the same results for influence expectations on economic KPIs and on bank-specific KPIs. Future research should use both measurement designs with the same KPIs to get comparable results. In this case, Cronbach's alpha could be compared.

Moreover, future research could consider a longitudinal design for self-efficacy and influence expectations on KPIs as in this study a cross-sectional design was used. As Bandura defined self-efficacy as context-specific (Bandura 1997), it may change within short periods of time (Ouweneel et al. 2013) as well as influence expectations on KPIs.

Variance explanation of $16 \%$ for job satisfaction and $18 \%$ for work engagement may be higher when taking further variables into analyses. Predictors for job satisfaction found in other studies are 
additional to self-efficacy e.g., self-esteem, internal locus of control, job autonomy, and emotional stability (Judge and Bono 2001; Federici 2013). Future research should consider these indicators also in their analysis additionally to self-efficacy and influence expectations on KPIs as this is a very complex topic.

\section{Conclusions}

Influence expectations on bank-specific KPIs are predictive of job satisfaction and influence expectations on economic KPIs are predictive of work engagement above and beyond professional self-efficacy. As employees are the link between environmental resources and outcome, the hidden assumption that employees should feel to have influence on KPIs for better job satisfaction and work engagement as well as performance is not fully supported. However, this study contributes to the importance for employees to know the goals of their company, e.g., with feedback systems of KPIs, to enhance job satisfaction and work engagement and further organizational productivity.

Author Contributions: A.L. and P.J. formulated the objectives, designed the method, supervised the data assessment, and worked together on the last draft of the paper. A.L. wrote the first draft of the paper, prepared the current state of the literature, and carried out the data assessment. A.L. analyzed the data with the support of N.T. N.T. supported the administration and quality assurance. All authors reflected the results and discussion.

Funding: This research received no external funding. This publication was printed with the financial support of the University of Graz.

Conflicts of Interest: The authors declare no conflict of interest.

\section{References}

Akinbobola, Olusola I., and Akinniyi A. Adeleke. 2013. The Influence of User Efficacy and Expectation on Actual System Use. Interdisciplinary Journal of Information, Knowledge, and Management 8: 43-57. [CrossRef]

Alessandri, Guido, Laura Borgogni, Wilmar B. Schaufeli, Gian Vittorio Caprara, and Chiara Consiglio. 2015. From Positive Orientation to Job performance: The Role of Work Engagement and Self-efficacy Beliefs. Journal of Happiness Studies 16: 767-88. [CrossRef]

Bakker, Arnold B., and Evangelia Demerouti. 2008. Towards a model of work engagement. Career Development International 13: 209-23. [CrossRef]

Bandura, Albert. 1997. Self-Efficacy: The Exercise of Control. New York: W.H. Freeman and Company.

Bandura, Albert. 2000. Cultivate Self-efficacy for Personal and Organizational Effectiveness. In The Blackwell Handbook of Principles of Organizational Behavior. Edited by Edwin A. Locke. Malden: Blackwell Publishers Ltd., pp. 179-200.

Bandura, Albert. 2006. Guide for Constructing Self-Efficacy Scales. In Self-Efficacy Beliefs of Adolescents. Edited by Frank Pajares and Tim Urdan. Charlotte: Information Age Pub., pp. 307-37.

Bandura, Albert. 2011. On the Functional Properties of Perceived Self-Efficacy Revisited. Journal of Management 38: 9-44. [CrossRef]

Behn, Robert. 2003. Why Measure Performance? Different Purposes Require Different Measures. Public Administration Review 63: 586-606. [CrossRef]

Blomquist, Tomas, Ali Dehghanpour Farashah, and J. Thomas. 2016. Project management self-efficacy as a predictor of project performance: Constructing and validating a domain-specific scale. International Journal of Project Management 34: 1417-32. [CrossRef]

Büssing, André, and Thomas Bissels. 1998. Different Forms of Work Satisfaction: Concept and Qualitative Research. European Psychologist 3: 209-18. [CrossRef]

Chhetri, Sabina Baniya. 2017. Antecedents and Consequences of Job Engagement: Empirical Study of Bank Employees. Business Perspectives and Research 5: 167-79. [CrossRef]

Cohen, Jacob. 1977. Statistical Power Analysis for the Behavioral Sciences. New York and London: Academic Press.

Collins, Andrew J., Patrick Hester, Barry Ezell, and John Horst. 2016. An improvement selection methodology for key performance indicators. Environ Syst Decis 36: 196-208. [CrossRef]

Dormann, Christian, and Dieter Zapf. 2001. Job satisfaction: a meta-analysis of stabilities. Journal of Organizational Behavior 22: 483-504. [CrossRef] 
Duffy, Ryan D., and Robert W. Lent. 2009. Test of a social cognitive model of work satisfaction in teachers. Journal of Vocational Behavior 75: 212-23. [CrossRef]

Federici, Roger A. 2013. Principals' self-efficacy: Relations with job autonomy, job satisfaction, and contextual constraints. European Journal of Psychology of Education 28: 73-86. [CrossRef]

Gelade, Garry A., and Stephen Young. 2005. Test of a service profit chain model in the retail banking sector. Journal of Occupational and Organizational Psychology 78: 1-22. [CrossRef]

Greve, Werner, Angelika Anderson, and Gunter Krampen. 2001. Self-Efficacy and Externality in Adolescence: Theoretical Conceptions and Measurement in New Zealand and German Secondary School Students. Identity: An International Journal of Theory and Research 1: 321-44. [CrossRef]

Guglielmi, Dina, Silvia Simbula, Wilmar B. Schaufeli, and Marco Depolo. 2012. Self-efficacy and workaholism as initiators of the job demands-resources model. Career Development International 17: 375-89. [CrossRef]

Heinrich, Tina. 2004. Resistance to Change_-Does Age Matter?: Predicting Negative Attitudes towards Organizational Change. London: Turnshare Ltd.

Hester, Patrick, Barry Ezell, Andrew J. Collins, John Horst, and Kaleen Lawsure. 2017. A Method for Key Performance Indicator Assessment in Manufacturing Organizations. International Journal of Operations Research 4: 157-67.

Jiménez, Paulino. 2006. Arbeitszufriedenheit als Mittlervariable in homöostatischen Feedbackprozessen. Eine kybernetische Perspektive [Job satisfaction as mediator variable in homeostatic feedback processes. A cybernetic perspective]. In Arbeitszufriedenheit: Konzepte und Empirische Befunde. Edited by Lorenz Fischer. Göttingen: Hogrefe, pp. 160-86.

Jiménez, Paulino, Borut Milfelner, Simona Šarotar Žižek, and Anita Dunkl. 2017. Moderating Effects between Job Insecurity and Intention to Quit in Samples of Slovene and Austrian Workers. Naše Gospodarstvo/Our Economy 63: 27-37. [CrossRef]

Jiménez, Paulino, Cornelia Schmon, Michaela Höfer, Angelika Lepold, Agnes Diebschlag, and Anita Dunkl. 2016. AWÖ 2015. Arbeitswelt österreich. Eine Studie zur Erfassung von Psychischer Belastung, Beanspruchung, Erholung und Zufriedenheit am Arbeitsplatz. [AWOe 2015. Working World in Austria. A Study for Assessing Mental Stress, Strain, Recovery and Satisfaction at the Workplace]. Bonn: Institut für Psychologie.

Judge, Timothy A., and Joyce E. Bono. 2001. Relationship of core self-evaluations traits-Self-esteem, generalized self-efficacy, locus of control, and emotional stability-With job satisfaction and job performance: A meta-analysis. Journal of Applied Psychology 86: 80-92. [CrossRef] [PubMed]

Judge, Timothy A., Howard M. Weiss, John D. Kammeyer-Mueller, and Charles L. Hulin. 2017. Job Attitudes, Job Satisfaction, and Job Affect: A Century of Continuity and of Change. Journal of Applied Psychology 102: 356-74. [CrossRef] [PubMed]

Kelloway, E. Kevin, and Julian Barling. 2010. Leadership development as an intervention in occupational health psychology. Work \& Stress 24: 260-79. [CrossRef]

Kocak, Recep, and Sevil Eves. 2010. The relationship between problem-solving and job-satisfaction of school administrators. Journal of Human Science 7: 193-212.

Krampen, Gunter. 2000. Handlungstheoretische Persönlichkeitspsychologie [Action-Oriented Personality Psychology]. Göttingen: Hogrefe.

Ladeira, Wagner Junior, Fernando De Oliveira Santini, Cláudio Hoffmann Sampaio, Marcelo Gattermann Perin, and Clécio Falcão Araújo. 2016. A meta-analysis of satisfaction in the banking sector. International Journal of Bank Marketing 34: 798-820. [CrossRef]

Leka, Stavroula, and Tom Cox. 2010. Psychosocial Risk Management at the Workplace Level. In Leka and Houdmont. Oxford: Wiley Blackwell, pp. 124-57.

Lepold, Angelika, Norbert K. Tanzer, Anita Bregenzer, and Paulino Jiménez. Forthcoming. The efficient measurement of job satisfaction: Facet-items versus facet scales. Unpublished Work.

Llorens, Susana, Wilmar B. Schaufeli, Arnold Bakker, and Marisa Salanova. 2007. Does a positive gain spiral of resources, efficacy beliefs and engagement exist? Computers in Human Behavior 23: 825-41. [CrossRef]

Luszczynska, A., Benicio Gutiérrez-Doña, and R. Schwarzer. 2005. General self-efficacy in various domains of human functioning: Evidence from five countries. International Journal of Psychology 40: 80-89. [CrossRef]

Maggiori, Christian, Claire S. Johnston, and Jérôme Rossier. 2015. Contribution of Personality, Job Strain, and Occupational Self-Efficacy to Job Satisfaction in Different Occupational Contexts. Journal of Career Development 43: 244-59. [CrossRef] 
Maté, Alejandro, Juan Trujillo, and John Mylopoulos. 2017. Specification and derivation of key performance indicators for business analytics: A semantic approach. Data \& Knowledge Engineering 108: 30-49. [CrossRef]

Mau, Wei-Cheng. 2000. Cultural Differences in Career Decision-Making Styles and Self-Efficacy. Journal of Vocational Behavior 57: 365-78. [CrossRef]

O'Driscoll, Michael P., and Paula Brough. 2010. Work Organization and Health. In Occupational Health Psychology. Edited by Leka Stavroula and Houdmont Jonathan. Hoboken: Wiley-Blackwell, pp. 57-88.

Ouweneel, Else, Pascale M. Le Blanc, and Wilmar B. Schaufeli. 2011. Flourishing students: A longitudinal study on positive emotions, personal resources, and study engagement. The Journal of Positive Psychology 6: 142-53. [CrossRef]

Ouweneel, Else, Wilmar B. Schaufeli, and Pascale M. Le Blanc. 2013. Believe, and You Will Achieve: Changes over Time in Self-Efficacy, Engagement, and Performance. Applied Psychology. Health and Well-Being 5: $225-47$. [CrossRef] [PubMed]

Paul, Catherine J. Morrison. 1999. Cost Structure and the Measurement of Economic Performance: Productivity, Utilization, Cost Economics, and Related Performance Indicators. Boston, Dordrecht and London: Kluwer Academic Publishers.

Rigotti, Thomas, Birgit Schyns, and Gisela Mohr. 2008. A Short Version of the Occupational Self-Efficacy Scale: Structural and Construct Validity Across Five Countries. Journal of Career Assessment 16: 238-55. [CrossRef]

Sahibzada, Umar Farooq, Khawaja Fawad Latif, B. Khan, and Mohsin Ullah. 2016. An Empirical Investigation into the Linkage of Self-Efficacy, Job Stress and Internal Service Quality. International Journal of Business Studies Review 1: 12-26.

Schaufeli, Wilmar B. 2018. Work engagement in Europe: Relations with national economy, governance and culture. Organizational Dynamics. [CrossRef]

Schaufeli, Wilmar B., and Arnold B. Bakker. 2003. UWES Utrecht Work Engagement Scale: Manual. Utrecht: Occupational Health Psychology Unit, Utrecht University.

Tims, Maria, Arnold B. Bakker, and Daantje Derks. 2014. Daily job crafting and the self-efficacy-Performance relationship. Journal of Managerial Psychology 29: 490-507. [CrossRef]

Tzur, Keren Stirin, Yoav Ganzach, and Asya Pazy. 2016. On the positive and negative effects of self-efficacy on performance: Reward as a moderator. Human Performance 29: 362-77. [CrossRef]

Vroom, Victor Harold. 1964. Work and Motivation. New York: Wiley.

Warr, Peter, and Ilke Inceoglu. 2012. Job Engagement, Job Satisfaction, and Contrasting Associations with Person-Job Fit. Journal of Occupational Health Psychology 17: 129-38. [CrossRef] [PubMed]

Wüpper, David, and Travis Lybbert. 2017. Perceived Self-Efficacy, Poverty and Economic Development. Annual Review of Resource Economics 9: 383-404. [CrossRef] 